\title{
Leadership and Emotional
}

\section{Intelligence: A Study of University Library Directors and Their Senior Management Teams}

\author{
Patricia A. Kreitz
}

Drawing on the results of a survey sent to library directors and senior management team members working in Association of Research Libraries member libraries in the Western United States, this study explores the ideal emotional intelligence traits of both academic library directors and the members of their senior management teams. Respondents were asked to identify the top ten ideal traits needed by directors and senior management team members. The study explores the extent to which each respondent agreed on the most important emotional intelligence traits for each organizational role. Results include lists of the top ten ideal traits for each organizational role and the top ten ideal shared traits for library leaders.

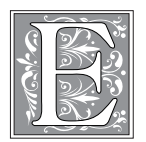

motional intelligence (EI), which deals with managing the emotional climate of an organization, has been called the "sine qua non of leadership." ${ }^{1}$ As Goleman originally conceived, EI consisted of five domains: self-awareness, self-regulation, motivation, empathy, and social skills. ${ }^{2}$ The first three domains encompass personal competencies or traits that focus on knowing and managing emotions in oneself, and the other two describe social competencies or traits that relate to knowing and managing emotions in others. ${ }^{3}$ Each domain had a varying number of traits, totaling 25 in all. These traits are composed of skills that can be learned and of abilities that, while originally innate, can be enhanced by training. ${ }^{4}$
In 2002, Goleman, together with Boyatzis and McKee, revised the EI model based on an examination of more than 600 corporate managers in a variety of settings and reorganized the five domains into four: self-awareness, self-management, social awareness, and relationship management. The original 25 traits were reduced to 18 . Goleman et al. observed that highly effective leaders typically show "strength in a half dozen or so EI ... [traits]" ${ }^{\prime \prime}$ enabling them to move workplace emotions in a positive direction. ${ }^{6}$

The number of EI traits possessed by leaders affects their degree of success in running organizations. ${ }^{7}$ A leader's high EI has been linked to the emotional climate

Patricia A. Kreitz is Director of Technical Information Services, SLAC National Accelerator Laboratory, Stanford University, and doctoral student in the Managerial Leadership in the Information Professions Program, Graduate School of Library and Information Studies, Simmons College, Boston; e-mail: pkreitz@ slac.stanford.edu. 
of an organization and its financial or operational success. ${ }^{8}$ Leadership, however, is not confined to one person (that is, to the boss). Others in the organization may also be leaders, influencing those whom they supervise ${ }^{9}$ and impacting the top leader's effectiveness. ${ }^{10}$

An organization's top leader seldom works directly with every staff member in an organization. Particularly in large or complex organizations, a senior management team aligns "the actions of larger numbers of people to the organization's vision and goals."11 If possessing a number of EI traits is valuable for the leader of an organization, perhaps it is equally valuable for the senior management team members.

\section{Problem Statement}

Leadership studies in academic libraries tend to focus on the library director. However, in university libraries, leadership is typically distributed between a director and those members of the senior management team who are in decisionmaking positions (for instance, associate or assistant university librarians). No study has examined the EI domains and traits that directors and their teams consider most important. This study fills that void by examining which traits both groups consider most important for a library director and a senior management team member to possess. It also explores the extent to which library directors and senior management team members agree on the most important EI traits for each organizational role.

Identifying which traits are most important to possess based on the leadership role the individual plays in an organization provides a more nuanced understanding of EI in leadership teams. Understanding which traits are identified as needed most for each organizational role will enable directors to deploy existing strengths more intentionally. It will also help senior management team members to identify and develop the traits most valuable for their organizational responsibilities. An increased EI awareness will also enable library directors to build strengths in areas where the entire team's collective skills are lacking. Thus, library directors can more fully manage their team's emotional intelligence skills and abilities and, through the team's effect on the emotional climate of the organization, increase the overall effectiveness of the library. In addition, understanding which EI traits are seen as most important for which leadership levels might have organizational implications for recruitment, retention, and succession planning and educational value in helping graduate schools and leadership institutes focus their training.

\section{Literature Review \\ General Writings}

In their comprehensive review of EI in the workplace, Zeidner et al. analyze the concept of EI and the associated set of traits in the occupational environment. ${ }^{12}$ They discuss some of the areas where concepts and terminology are unclear in the research literature, but they conclude that "over three decades of psychological assessment research has vindicated the importance of taking social and emotional traits into consideration when attempting to predict occupational effectiveness." 13

Much of the research on workplace effectiveness focuses on the top leader to identify what traits comprise effective leadership. A popular assumption is that leader effectiveness translates into organizational effectiveness. ${ }^{14}$ This assumption is borne out by research that links the degree of EI a leader demonstrates to workplace measures of the leader's or the organization's success. ${ }^{15}$

Dulewicz and Higgs' research on the EI traits of individual business leaders supports the top-leader-centric focus of EI studies. ${ }^{16}$ Using data from their 1995 study of traits from boards of directors and data from their 1999 study of general managers from a variety of countries, they identified those traits related to EI. They found that "the elements of EI are 
amongst some of the important attributes required for effective leaders," and that "the higher one rises within an organization, the more important EI becomes." ${ }^{17}$

Leaders with positive emotional styles enhance the ability of followers to engage effectively in problem solving and creativity. ${ }^{18}$ Studies have found that leader EI is particularly influential on team performance. ${ }^{19}$ Among the evidence of the importance of EI is an analysis of sales managers, which showed a positive correlation between the leader's mood and the financial performance of the sales force. ${ }^{20}$ Rosete and Ciarrochi, who studied senior managers in the Australian public service sector, found that leader EI positively correlated to workplace performance both at an individual leader level and an organizational level. ${ }^{21}$ In academic settings, Heiken identified "a modest positive relationship between emotional intelligence and the practice of leadership" among school administrators, ${ }^{22}$ while Tang found significant correlation between the EI and measures of leadership effectiveness of both U.S. and Taiwanese academic leaders. ${ }^{23}$ Noble's analysis showed that EI traits are frequently listed in job advertisements for community college deans. ${ }^{24}$

Researchers conducting leadership and management studies advocate for a more complex, nuanced approach to studying leadership within organizations. In particular, O'Toole, Galbraith, and Lawler argue that a monocentric focus on the top leader may be culturally biased, and there is a need to develop a new model where "leadership would come to be thought of as a team sport." 25 They argue that, because of increasing complexity, "shared leadership has become almost a necessity when it comes to leading change within organizations." ${ }^{26}$ EI's importance in the success of work teams has been extensively researched. ${ }^{27}$ Analyzing the traits that distinguish effective teams from mediocre ones, Druskat and Goleman found that the most distinguishing characteristics were all EI traits. ${ }^{28}$ As Goleman et al. argue, the "team at the top" needs to maximize its effectiveness by putting its "emotional intelligence to work." 29

Carmeli examined senior chief financial officers in government agencies who possessed a high level of EI and then analyzed the extent to which their EI correlated with other measures of work attitudes and outcomes. The more EI traits possessed, Carmeli found, the higher the positive correlation with work attitudes and work performance. He concluded that his findings were important for organizations "which recognize the critical role the top management team plays in their success." ${ }^{30}$ Gardner and Stough's examination of EI in "high level" managers showed a statistically significant relationship between transformational leadership and overall emotional intelligence. ${ }^{31} \mathrm{~A}$ transformational leader uses many EI traits by inspiring followers to commit to a shared organizational vision and goals, challenging followers to achieve extraordinary outcomes, and mentoring and coaching followers to develop their own leadership capacities. ${ }^{32}$ Since transformational leadership styles correlated positively with leadership effectiveness, Gardner and Stough concluded that EI assessment could be used to identify and develop those managers with leadership potential.

\section{Library and Information Science Literature}

Much of the research and writing on library leadership mirrors the more popular approach of general management and leadership studies - that of focusing on the leader at the top. Expanding one area of a leader's traits, Hernon and Rossiter used Goleman's original five domains (to study the EI traits of directors of libraries with membership in the Association of Research Libraries [ARL]). ${ }^{33}$ They identified those traits that directors considered the most important for a director to possess. In follow-up interviews with a subset of directors, they found that many of those interviewed believed that, while no one person could master all the EI traits, 
the director and "the senior management team, as a whole, would possess the entire set." ${ }^{34}$ Hernon extended his work on the most important EI traits valued by library leaders by comparing the four EI domains and traits with attributes developed from the distributed model of leadership. ${ }^{35}$

\section{Study Hypotheses}

The study proposed two hypotheses:

1. There will be no statistically significant difference $(p=.05)$ between the traits that library directors (LDs) choose for a director and the traits they choose for a senior management team member (SMT).

2 . There will be no statistically significant difference $(p=.05)$ between the traits that senior management team members (SMTs) choose for a director and the traits they choose for a senior management team member (SMT).

\section{Procedure}

\section{Participants}

The potential study population was staff from 19 academic libraries that are ARL members and located in the region of the Western United States: Alaska, Arizona, California, Colorado, Hawaii, Idaho, Montana, New Mexico, Nevada, Oregon, Utah, Washington, and Wyoming. ${ }^{36}$ Table 1 identifies those 19 ARL member libraries. Between November 2006 and January 2007, when the author was contacting directors to determine willingness to participate, the director's position was vacant in six libraries, reducing the study group to 13 .

\begin{tabular}{|l|c|c|c|c|c|c|}
\hline \multicolumn{7}{|c|}{ TABLE 1 } \\
\multicolumn{1}{|c|}{ Western Regional ARL Libraries } \\
\hline \hline \multicolumn{1}{|c|}{ ARL Library } & State & $\begin{array}{c}\text { Director } \\
\text { Position }\end{array}$ & Participation* & Reason & $\begin{array}{c}\text { LD/SMT } \\
\text { Total } \\
\text { Sent }\end{array}$ & $\begin{array}{c}\text { LD/SMT } \\
\text { Number } \\
\text { Returned }\end{array}$ \\
\hline Arizona State University & AZ & Filled & NP & Declined & 0 & \\
\hline Univ. of Arizona & AZ & Filled & NP & Declined & 0 & \\
\hline Brigham Young. Univ. & UT & Filled & P & & 5 & 3 \\
\hline UC Berkeley & CA & Filled & NP & Declined & 0 & \\
\hline UC Davis & CA & Filled & NP & SMT & 0 & \\
\hline UC Irvine & CA & Vacant & NQ & Disqualified & & \\
\hline UC Los Angeles & CA & Filled & P & & 8 & 5 \\
\hline UC Riverside & CA & Filled & P & & 4 & 1 \\
\hline UC San Diego & CA & Filled & NP & Declined & 0 & \\
\hline UC Santa Barbara & CA & Vacant & NQ & Disqualified & & \\
\hline Univ. Colorado & CO & Filled & P & & 4 & 4 \\
\hline Colorado State Univ. & CO & Filled & P & & 4 & 3 \\
\hline Univ. Hawaii & HI & Vacant & NQ & Disqualified & & \\
\hline Univ. New Mexico & NM & Vacant & NQ & Disqualified & & \\
\hline Univ. Oregon & OR & Filled & P & & 3 & 3 \\
\hline Univ. Southern California & CA & Vacant & NQ & Disqualified & & \\
\hline Univ. Utah & UT & Filled & P & & 11 & 5 \\
\hline Univ. Washington & WA & Filled & P & & 8 & 4 \\
\hline Washington State Univ. & WA & Vacant & NQ & Disqualified & & \\
\hline * P = Participating institution; NP $=$ Non-participating institution; NQ Not qualified to participate \\
\hline
\end{tabular}


In addition to identifying the study population, table 1 indicates the number of LDs and SMTs in each library. The senior management teams, excluding the directors, range in size from 2 to 13. In some libraries, SMTs were responsible for traditional organizational divisions such as public or technical services. In other libraries, directors defined the senior management team more broadly, including financial or personnel officers or representatives of the library faculty or support staff.

Once the institutional review boards of Simmons College and Stanford University approved the study, an initial e-mail message describing the study and requesting the library's participation was sent to the 13 directors, with a follow-up telephone call two weeks later. Contact via phone and e-mail continued until every LD responded. Of the 13 libraries contacted, eight agreed to participate. After a director communicated the library's agreement to participate, each LD or SMT was mailed a copy of the survey instrument, together with a cover letter, two copies of the consent form (one to be signed and returned with the survey, one for the respondent's records), and a stamped addressed envelope to return the completed survey to the author.

\section{Measures}

Pretesting the survey instrument. The study consists of two parts; the first is the reorganization and pretesting of the survey instrument that Hernon and Rossiter used to study ARL library directors, and the second is the survey itself. ${ }^{37}$ The original five domains and associated traits used were mapped to the revised four domains: self-awareness, self-management, social awareness, and relationship management. The traits were redistributed and then pretested using five volunteers whose libraries were not part of the study population, including two library directors, two senior management team members, and one human resources director.
The individuals engaged in the pretest were asked to determine whether the traits from the original fifth domain were appropriately distributed in the new four-domain model. In two instances, when more than one pretester suggested moving a trait from one domain to another, those traits were relocated. In three cases where only one pretester suggested changing a trait's domain, the author conducted a phone interview with the pretester to determine how important the change was. When pretesters disagreed about where the trait should be located (two instances), the final decision was made by the pretester who was the human resources director. Based on feedback that Hernon and Rossiter received from some directors, respondents to this survey instrument were asked to identify their top 10 traits in each domain. ${ }^{38}$ Several pretesters advised that most LDs and SMTs would not be comfortable responding unless it was clear that they were not being asked to rate their current library director or team members.

Final survey instrument. In response, the survey directions and section subtitles were modified so that respondents were asked to identify and rank the top 10 traits for an ideal library director and an ideal senior management team member in four domains: self-awareness, self-management, social awareness, and relationship management (see Appendix for a complete listing of traits organized into the four domains with domain definitions). Respondents had the option in each domain to add additional traits. Three respondents each added one trait in the self-awareness domain. In each domain, respondents ranked the top 10 traits for an ideal LD and the top 10 traits for an ideal SMT. Respondents originally ranked traits as $1=$ high rank and $10=$ low rank, but all traits were recoded $1=$ low and $10=$ high. Any trait not ranked between 1 and 10 was coded 0 so that all cells had a value and no data would be missing for the statistical analyses comparing ranks. 


\section{Data Analysis}

Frequencies were generated for all traits. Traits were ranked from highest to lowest based on their means, and then the traits with the ten highest means were selected for each group, by domain. Where there were ties in trait means, all traits up to the trait with the 10th highest mean are listed. If library directors (LDs) ranked a trait for a particular role highly but senior management team members (SMTs) did not, SMT rankings are still presented for the trait for the sake of comparison, and if SMTs ranked a trait highly but LDs did not, the LDs' trait information was still similarly shown.

After the top items were identified for each role in each domain, the mean ranks for LDs' perceptions of a trait for a specific organizational role were compared to SMT perceptions of the same trait for the same role, using the Mann-Whitney U test that compared director and SMT rankings for each trait for each role. For example, this test was used to compare LD and SMT perceptions of the importance of selfconfidence in the LD's role. Mean ranks are presented in the tables that follow, along with the $Z$ statistic that was used to assess the statistical significance of the difference in ranks. Additionally, to compare LDs' and SMTs' perceptions of the value of the same competence for both the LD role and the SMT role, Wilcoxon signed rank tests were conducted. The Wilcoxon signed rank test, a nonparametric test, was used because the data were rank data and not symmetrical about the median. It is useful in determining the significance of the difference between two correlated samples-that is, LDs' perceptions both of the LD and SMT role. Similar analyses were conducted to compare SMT perceptions of the value of the same competence for SMT and LD roles. Where signed rank tests indicated that LDs or SMTs valued a trait more highly for one role than another, superscript letters designate these traits in the tables that follow.

Next, analyses identified traits that both LDs and SMTs agreed were impor- tant for either the LD role or the SMT role. Frequencies were run to obtain means and standard deviations for these items for the sample as a whole. For each role, the items with the highest five means (including any in which the ranks were tied) were selected and shown. As above, differences in the overall ranking of these items among each other were compared using nonparametric Friedman's rank test. Where the analysis showed that the mean ranks did not differ significantly from each other, they were designated as having a comparable rank. Where the analyses identified significant differences in ranks, these are marked in the tables that follow.

Finally, analyses then identified traits that both LDs and SMTs agreed were important across both leadership roles. Each group's rankings of the importance of traits in the LD and SMT role were averaged into one value for the sample as a whole, controlling for the different size of the two initial sets of rankings. Frequencies were run to obtain means and standard deviations for these items again for the sample as a whole. The items with the highest 5 means (including any in which the ranks were tied) were selected. Differences in the overall rankings among these items were compared using Friedman's rank tests. Where the analyses identified significant differences in ranks, these are indicated in the tables that follow.

\section{Results}

Eight libraries out of 13 agreed to participate, providing 47 potential LD and SMT respondents. The number of returned surveys totaled 28 with 6 LDs and 22 SMTs, resulting in a 60 percent response rate (see table 1). One returned survey was eliminated due to ranking errors, leaving $21 \mathrm{SMT}$ responses. In the tables for each domain, traits were abbreviated.

Self-awareness domain. Table 2 shows frequencies and mean ranks for the importance of self-awareness traits for both an ideal LD and an ideal SMT ranked by the LDs and by the SMTs. Traits are listed 
Leadership and Emotional Intelligence 537

\begin{tabular}{|c|c|c|c|c|c|c|c|c|c|c|c|c|c|c|c|c|c|c|c|c|c|}
\hline \multirow{5}{*}{\multicolumn{2}{|c|}{ | }} & & $\mathbf{N}$ & $\vec{\imath}$ & $\stackrel{8}{8}$ & $\stackrel{n}{\infty}$ & $\stackrel{m}{i}$ & $\stackrel{*}{\stackrel{*}{\leftrightarrows}}$ & $\hat{g}_{i}$ & $\begin{array}{l}\infty \\
? \\
?\end{array}$ & & 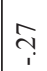 & $\stackrel{m}{\longrightarrow}$ & & ô. & $\stackrel{n}{i}$ & $\stackrel{\sim}{\leftrightarrows}$ & & $\hat{o}_{i}$ & $\stackrel{?}{\stackrel{q}{i}}$ & 0 \\
\hline & & 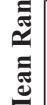 & $\sum_{\infty}^{E}$ & $\begin{array}{l} \pm \\
\pm \\
\pm\end{array}$ & خे & $\stackrel{m}{m}$ & $\begin{array}{l}\stackrel{\circ}{ \pm} \\
\stackrel{+}{ \pm}\end{array}$ & $\stackrel{i}{n}$ & $\begin{array}{l}\stackrel{n}{n} \\
\stackrel{n}{n}\end{array}$ & $\begin{array}{l}\stackrel{n}{+} \\
\dot{ \pm}\end{array}$ & & $\begin{array}{l}\stackrel{\vartheta}{2} \\
\stackrel{2}{2}\end{array}$ & 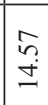 & & $\stackrel{\overbrace{}}{\stackrel{g}{g}}$ & $\begin{array}{l}0 \\
\dot{0} \\
\pm \\
\end{array}$ & $\begin{array}{l}\infty \\
\infty \\
\dot{ \pm}\end{array}$ & & $\begin{array}{l}\tilde{\sigma} \\
\dot{m}\end{array}$ & $\stackrel{m}{m}$ & $\begin{array}{l}\overrightarrow{0} \\
\text { : } \\
0 \\
0 \\
0 \\
0\end{array}$ \\
\hline & & & a & $\begin{array}{l}\stackrel{0}{n} \\
\stackrel{m}{n}\end{array}$ & in & గై & $\begin{array}{l}\hat{\sigma} \\
\tilde{2}\end{array}$ & 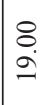 & $\begin{array}{l}\stackrel{n}{2} \\
\stackrel{i}{2}\end{array}$ & 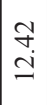 & & $\begin{array}{l}\stackrel{n}{\curvearrowright} \\
\dot{\Xi}\end{array}$ & $\begin{array}{l}\stackrel{8}{0} \\
\text { i }\end{array}$ & & $\begin{array}{l}8 \\
0 \\
0\end{array}$ & $\begin{array}{l}\widetilde{\sigma} \\
=\end{array}$ & Sू & & $\stackrel{\Xi}{ \pm}$ & $\begin{array}{l}0 \\
\infty \\
\text { I }\end{array}$ & 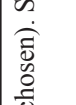 \\
\hline & & $\sum_{\infty}^{\infty}$ & 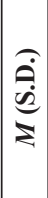 & 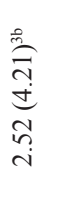 & 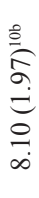 & 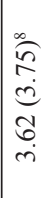 & 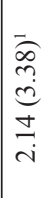 & 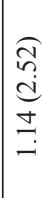 & 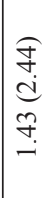 & 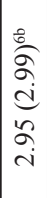 & & 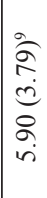 & $\begin{array}{l}\widetilde{\approx} \\
\tilde{n} \\
\tilde{n} \\
\infty \\
\infty \\
\tilde{m}\end{array}$ & & $\begin{array}{l}\stackrel{0}{\widehat{\sigma}} \\
\stackrel{\infty}{=} \\
\stackrel{\infty}{+}\end{array}$ & 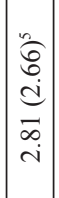 & $\begin{array}{l}\widehat{\pi} \\
\tilde{n} \\
\tilde{c} \\
\infty \\
m \\
m \\
m\end{array}$ & & 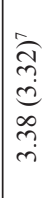 & 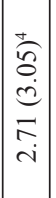 & $\begin{array}{l}\overrightarrow{0} \\
\| \\
0 \\
0 \\
\tilde{0} \\
0 \\
0 \\
0 \\
0 \\
0\end{array}$ \\
\hline & & $\hat{ق}$ & 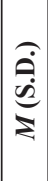 & 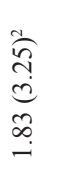 & 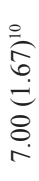 & 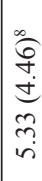 & 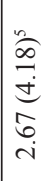 & $\begin{array}{l}\widehat{\widehat{\sigma}} \\
\tilde{y} \\
\hat{\jmath} \\
\dot{\sigma} \\
\dot{m}\end{array}$ & 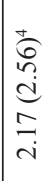 & 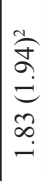 & & $\begin{array}{l}a \\
6 \\
n \\
0 \\
\tilde{c} \\
\hat{\sigma} \\
\dot{0}\end{array}$ & $\begin{array}{l}n \\
\hat{n} \\
\tilde{n} \\
\tilde{n} \\
8 \\
0 \\
i\end{array}$ & & 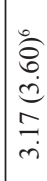 & $\left|\begin{array}{c}1 \\
\sigma \\
n \\
\tilde{d} \\
n \\
\infty \\
-i\end{array}\right|$ & $\begin{array}{l}\tilde{n} \\
\tilde{n} \\
m \\
0 \\
8 \\
8 \\
i \\
i\end{array}$ & & 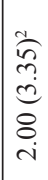 & 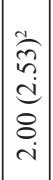 & 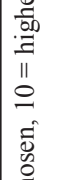 \\
\hline \multirow{6}{*}{ N } & \multirow{6}{*}{ 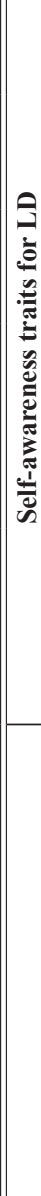 } & \multirow{3}{*}{ 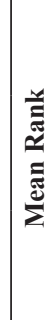 } & $\mathbf{N}$ & $\stackrel{\infty}{\text { i }}$ & $\approx$ & กี & $\stackrel{9}{\rightarrow}$ & $\stackrel{\infty}{\stackrel{\infty}{\sim}}$ & $\underset{i}{q}$ & $\frac{\vec{\sigma}}{i}$ & $\underset{8}{8}$ & ?ִ & $\hat{o}_{i}$ & ț & $\stackrel{\infty}{2}$ & $\tilde{i}$ & $\underset{\infty}{\infty}$ & $\frac{\text { t }}{i}$ & & & $\begin{array}{l}\overrightarrow{0} \\
0 \\
0 \\
0 \\
0\end{array}$ \\
\hline & & & $\sum_{\infty}^{E}$ & $\begin{array}{l}\hat{\sigma} \\
\dot{ \pm}\end{array}$ & 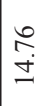 & $\begin{array}{l}8 \\
\ddot{2}\end{array}$ & $\stackrel{\mathscr{2}}{\stackrel{I}{I}}$ & $\begin{array}{l}n \\
0 \\
n \\
n\end{array}$ & $\begin{array}{l}\tilde{\sigma} \\
\stackrel{\sigma}{2} \\
\tilde{2}\end{array}$ & $\begin{array}{l}\stackrel{+}{\sim} \\
\ddot{n}\end{array}$ & $\frac{\partial}{\stackrel{2}{2}}$ & 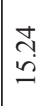 & $\begin{array}{l}\qquad \hat{c} \\
\dot{J}\end{array}$ & 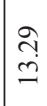 & $\begin{array}{l}\stackrel{\vartheta}{ \pm} \\
\dot{ \pm}\end{array}$ & $\begin{array}{l}\stackrel{\Xi}{Ð} \\
\dot{\Xi}\end{array}$ & $\begin{array}{l}\widetilde{\sigma} \\
\dot{ \pm}\end{array}$ & $\begin{array}{l}\infty \\
\infty \\
\pm\end{array}$ & & & 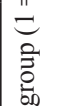 \\
\hline & & & a & $\stackrel{\infty}{\stackrel{n}{=}}$ & $\stackrel{m}{=}$ & 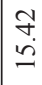 & $\begin{array}{l}\tilde{n} \\
\infty \\
\infty\end{array}$ & $\stackrel{m}{\stackrel{n}{I}}$ & $\stackrel{m}{n}$ & $\begin{array}{l}\hat{6} \\
6 \\
-\end{array}$ & $\begin{array}{l}\tilde{\infty} \\
0 \\
0 \\
-1\end{array}$ & $\hat{\sigma}$ & $\begin{array}{l}\tilde{\infty} \\
\tilde{\sigma}\end{array}$ & $\begin{array}{l}0 \\
n \\
0 \\
0\end{array}$ & $\stackrel{\sim}{\stackrel{n}{=}}$ & $\stackrel{\stackrel{f}{\Xi}}{=}$ & $\stackrel{\infty}{\infty}$ & $\stackrel{8}{\stackrel{8}{\Xi}}$ & & & \\
\hline & & $\sum_{i}^{\infty}$ & 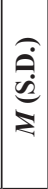 & 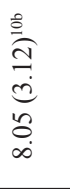 & 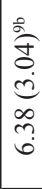 & 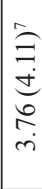 & 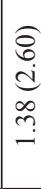 & 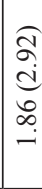 & 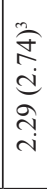 & 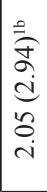 & 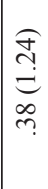 & 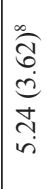 & 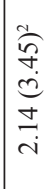 & 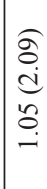 & 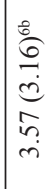 & 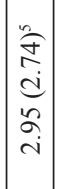 & 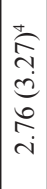 & 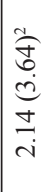 & & & 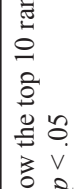 \\
\hline & & $\stackrel{\mathrm{a}}{\mathrm{a}}$ & $\begin{array}{c}2 \\
\dot{a} \\
\dot{a} \\
z\end{array}$ & 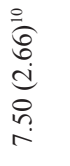 & 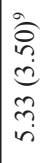 & $\begin{array}{l}\underset{\hat{\sigma}}{\infty} \\
\underset{+}{+} \\
\tilde{m} \\
\dot{+}\end{array}$ & 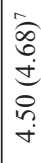 & $\begin{array}{l}\stackrel{\circ}{\Im} \\
\stackrel{+}{+} \\
\stackrel{8}{8} \\
\stackrel{+}{+}\end{array}$ & 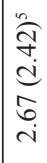 & 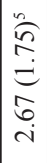 & 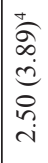 & 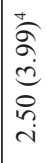 & $\begin{array}{l}\tilde{\hat{\jmath}} \\
\infty \\
\tilde{c} \\
\tilde{n} \\
\tilde{n} \\
\tilde{c}\end{array}$ & 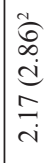 & 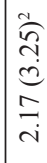 & 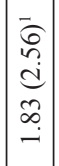 & 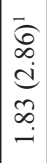 & $\begin{array}{l}\hat{8} \\
\dot{0} \\
\dot{0} \\
\dot{8}\end{array}$ & & & 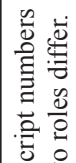 \\
\hline & & & & 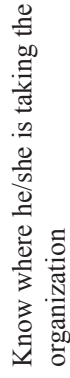 & 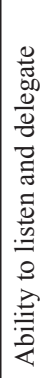 & 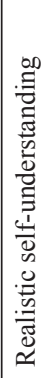 & 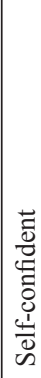 & 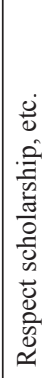 & 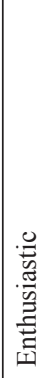 & 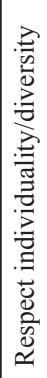 & 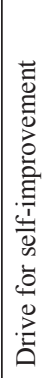 & 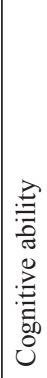 & 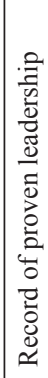 & 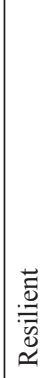 & & 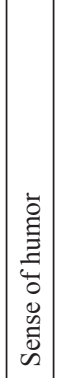 & 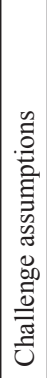 & 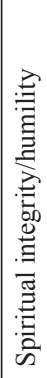 & 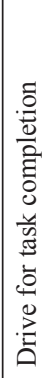 & 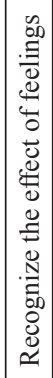 & 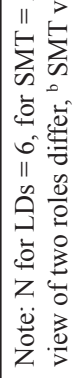 \\
\hline
\end{tabular}


in descending rank order as ranked by the LDs for the ideal LD.

The table indicates that LDs identified the top five traits for an ideal LD as: knowing where he or she is going/taking the organization, ability to listen and delegate, realistic self-understanding of oneself, self-confidence, and respect for scholarship, learning, and teaching. The SMTs agreed with three of the LDs' top ranked traits: knowing where they are taking the organization, being able to listen and delegate, and possessing realistic self-understanding, but added two more: cognitive ability and being articulate.

LDs and SMTs also ranked the ability to listen and delegate and the trait of possessing a realistic understanding of oneself among the five most important for an ideal SMT. The trait of the cognitive ability to deal with complex scenarios or situations was also rated as important for the ideal SMT by both LDs and SMTs. LDs rated respecting scholarship, learning, and teaching as more important for an ideal SMT than SMTs did for their role.

Superscript letters in table 2 indicate where the LDs or SMTs ranked traits as different in importance for an ideal individual in his or her role compared to an ideal individual in the other group's role. Superscript $\boldsymbol{a}$ indicates that the LDs' view of the importance of the trait for each of the roles differed significantly $(p<.05)$. Superscript $\boldsymbol{b}$ indicates that the SMTs' view of the importance of a trait for each of the roles differed significantly $(p<$ .05). For example, table 2 shows that both LDs and SMTs rated the trait of knowing where he or she is taking the organization as more important for an ideal LD than for an ideal SMT. SMTs ranked both the ability to listen and delegate and the ability to respect individuality and diversity as more important traits for their role than for the LD role. LDs considered it more important for an SMT to be articulate than SMTs considered it to be for an ideal individual in the SMT role.

Self-management domain. Table 3 shows the frequencies and mean ranks for the importance of the self-management domain traits for both an ideal LD and an ideal SMT ranked by the LDs and by the SMTs. Traits are listed in descending rank order as ranked by the LDs for the ideal LD.

The table indicates that LDs identified the top five traits (with one tie) that an ideal LD should have as: articulating a direction for the library; integrity; a commitment to job, organization, and profession; honesty; being comfortable with change; and having skill at diagnostic, strategic, and tactical reasoning. The SMTs agreed with two of those: articulating a direction for the library and integrity. However, the top five traits SMTs listed as most important for an ideal LD also included (with one tie) being innovative/creative, having a broad knowledge of issues, being comfortable in making judgment calls, and asking the "right/tough" questions. LDs ranked the trait of being driven to achieve beyond expectations as a more important trait for an LD than SMTs did.

LDs and SMTs also ranked having integrity, having a broad knowledge of issues, and being comfortable with change as among the five most important self-management traits for an ideal SMT. LDs rated commitment to job, organization, and profession as more important for an ideal SMT than SMTs rated it for their own role. Both LDs and SMTs rated the ability to articulate a direction for the library as more important for an ideal LD than for an SMT. For the trait of being innovative/creative, LDs did not rank it among their top ten for either leadership role. SMTs, however, ranked it the eighth highest self-management trait for ideal LDs to possess and ninth highest for an ideal SMT to possess.

Social awareness domain. Table 4 shows the frequencies and mean ranks for the importance of social awareness domain traits for both the ideal LD and SMT ranked by the LDs and by the SMTs. Traits are listed in descending rank order as ranked by the LDs for the ideal LD. 
Leadership and Emotional Intelligence 539

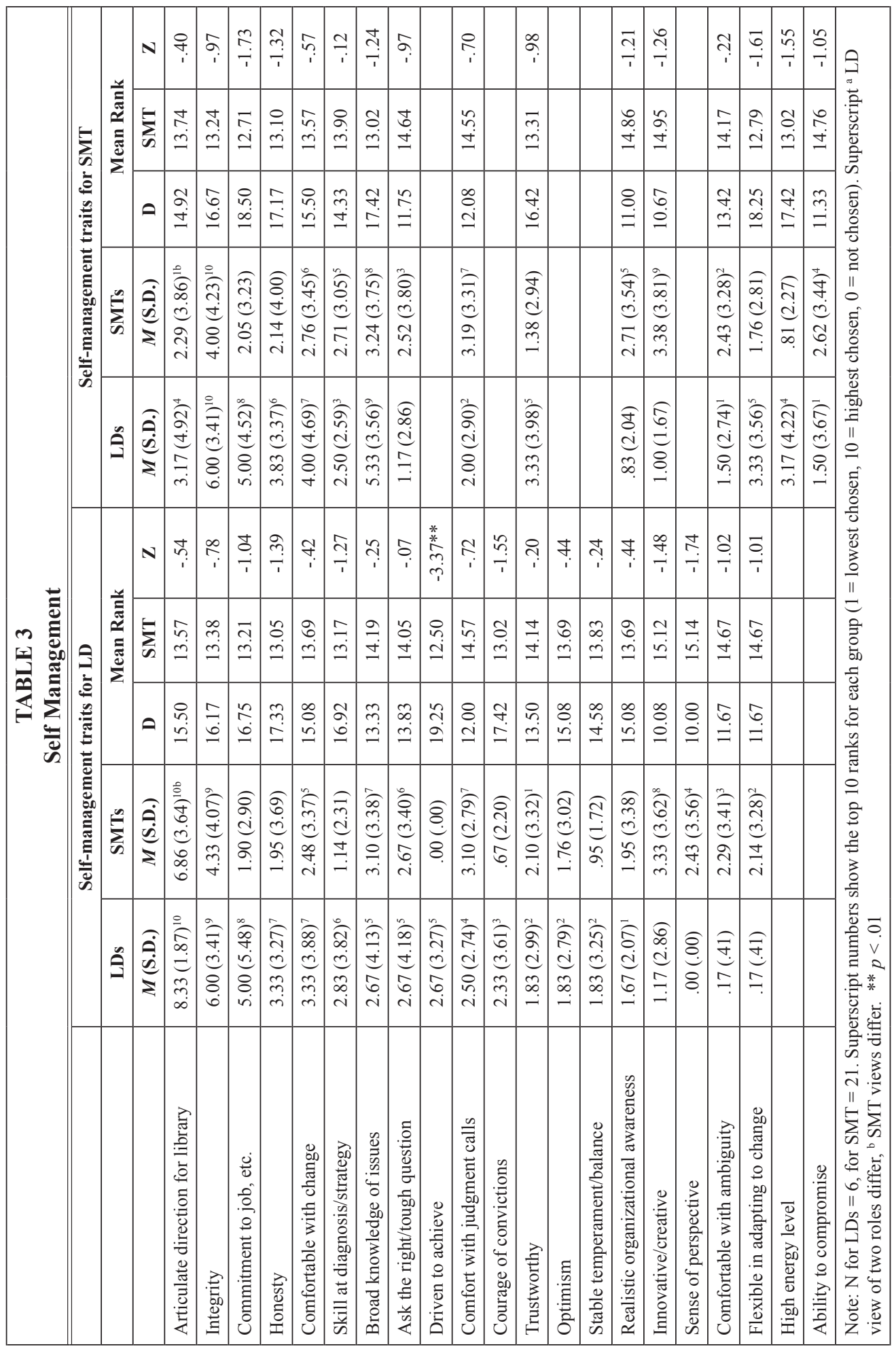




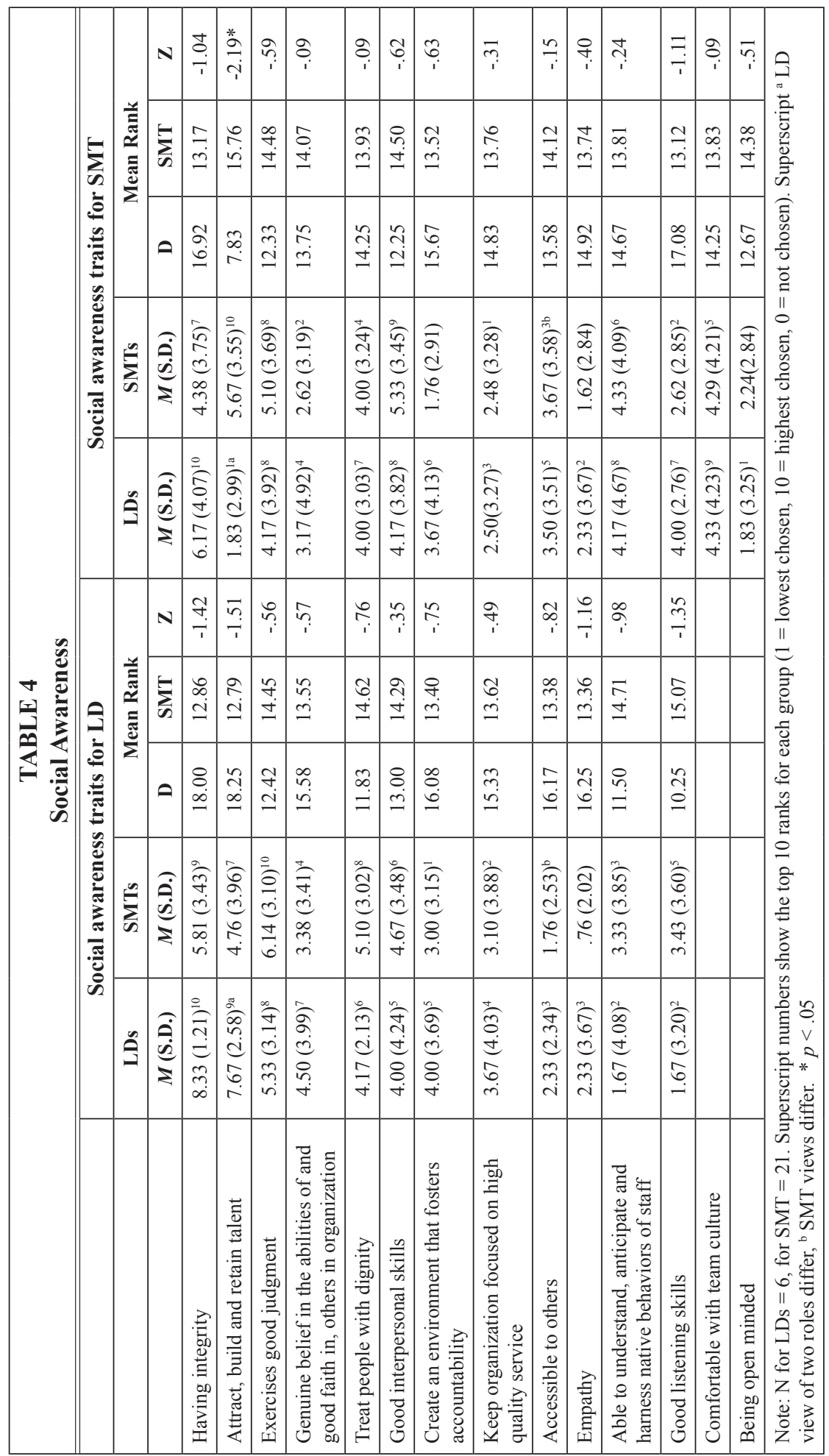


LDs identified the top five traits for an ideal LD as: having integrity; ability to attract, build, and retain talent; exercising good judgment; having a genuine belief in the abilities of, and the good faith of, others; and treating others with dignity/ respect. The SMTs agreed with four of the ideal LD traits that LDs chose but also included having good interpersonal skills among their top five competencies for an ideal LD. LDs ranked it next highest in their list, just missing their top five.

LDs and SMTs also ranked integrity and good judgment as important social awareness traits for an ideal SMT. Good interpersonal/people skills; the ability to understand, anticipate, and harness staff; and comfort with team culture were rated as important for the ideal SMT by both LDs and SMTs. SMTs rated the most important trait for an SMT as the ability to attract, build, and retain talent; however, LDs did not consider this an important trait for an ideal SMT and rated it as significantly less important for an SMT than for themselves. The SMTs considered it more important that an ideal SMT be accessible to others than that an ideal LD be accessible. Correspondingly, LDs considered it less important for the LD than for SMTs to have good listening skills.

Relationship management domain. Table 5 shows the frequencies and mean ranks for the importance of relationship management domain traits for both an ideal LD and an ideal SMT ranked by the LDs and by the SMTs. Traits are listed in descending rank order as ranked by the LDs for the ideal LD.

Table 5 indicates that LDs identified the top five relationship management traits an ideal LD should have as: being visionary - able to build a shared vision and rally others around it; being effective in leading change; being able to motivate people to develop and adhere to a shared vision; being able to change/shape the library's culture; and being able to bring issues of broad importance to the academic community. The SMTs agreed with three of the LDs' choices, listing as among their top five LD traits: being visionary, effective in leading change, and able to motivate people to adhere to a shared vision. Traits SMTs listed in their top five for an ideal LD also included the ability to function in a political environment and ability to gather outside resources.

Table 5 shows that LDs and SMTs had more consensus on the relationship management traits an ideal LD should possess and less consensus on the traits each group identified for an ideal SMT. LDs rated the top traits (with one tie) for the ideal SMT as: an ability to change/shape the library's culture, being collaborative, having resonance (inspiring people to work together), leading in a shared decision-making environment, being an enabler and facilitator, and possessing expertise in building and leading teams. Of those traits that the LDs chose for an ideal SMT, the SMTs agreed with one, that of leading in a shared decision-making environment. The other four top relationship management traits SMTs considered most important for the ideal SMT were: being effective in leading change, motivating people to develop and adhere to a shared vision, having the ability to function in a political environment, and engaging in consensus building in carrying out strategic direction.

SMTs chose three traits as important for both LDs and SMTs to possess: being effective in leading change, motivating people, and functioning in a political environment. LDs considered it significantly more important for LDs to be able to motivate people to develop a shared vision than for SMTs to employ that trait. SMTs considered the traits of being able to both build consensus and to lead in a shared decision-making environment as more important for the ideal SMT than for the ideal LD.

Ideal director traits. Table 6 shows the frequencies and mean ranks for responses about traits that both groups considered the most important for the LD's role. Traits marked with a superscript 1 were rated as significantly more important than traits 


\begin{tabular}{|c|c|c|c|c|c|c|c|c|c|c|c|c|c|c|c|c|c|c|c|c|c|}
\hline \multirow{5}{*}{\multicolumn{2}{|c|}{$\mid$}} & \multirow{3}{*}{ 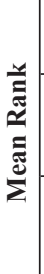 } & $\mathbf{N}$ & & b. & ఫ) & \$. & & 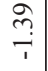 & $\tilde{n}$ & $\stackrel{\infty}{\stackrel{\infty}{\rightarrow}}$ & & $\underset{i}{\stackrel{7}{7}}$ & & $\vec{\imath}$ & $\dot{g}_{i}$ & & $\frac{\tilde{\sigma}}{\rightarrow}$ & $\stackrel{m}{?}$ & $\stackrel{n}{\rightarrow}$ & \multirow{5}{*}{ 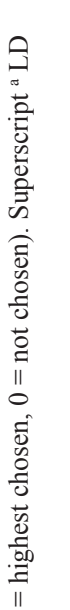 } \\
\hline & & & $\sum_{\infty}$ & & 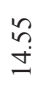 & $\begin{array}{l}\text { ț } \\
\dot{\Xi}\end{array}$ & $\begin{array}{l}\stackrel{0}{n} \\
\stackrel{n}{n}\end{array}$ & & $\begin{array}{l}0 \\
\cong \\
\cong\end{array}$ & $\begin{array}{l}n \\
n \\
n\end{array}$ & $\begin{array}{l}\hat{a} \\
\dot{m}\end{array}$ & & $\begin{array}{l}\stackrel{0}{J} \\
\underset{J}{J}\end{array}$ & & $\begin{array}{l}\Xi \\
\pm \\
\pm\end{array}$ & $\begin{array}{l}\hat{\sigma} \\
\dot{ \pm}\end{array}$ & & $\overrightarrow{\stackrel{a}{a}}$ & $\stackrel{+}{\stackrel{\sim}{2}}$ & 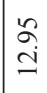 & \\
\hline & & & $\theta$ & & $\begin{array}{l}\infty \\
\stackrel{0}{ } \\
\stackrel{I}{J}\end{array}$ & $\stackrel{n}{\beth}$ & ֶิ & & $\stackrel{-}{\circ}$ & $\begin{array}{l}\infty \\
n \\
n \\
n\end{array}$ & 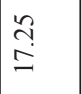 & & 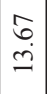 & & $\begin{array}{l}\stackrel{I}{\leftrightarrows} \\
\stackrel{\sim}{2}\end{array}$ & $\begin{array}{l}\stackrel{n}{n} \\
\dot{m}\end{array}$ & & $\begin{array}{l}0 \\
\infty \\
\infty \\
0\end{array}$ & $\begin{array}{l}\alpha \\
\dot{I}\end{array}$ & 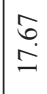 & \\
\hline & & $\sum_{\infty}^{n}$ & 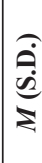 & & 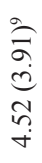 & 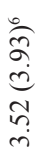 & 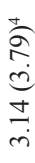 & & 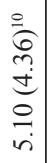 & 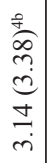 & 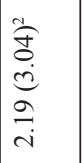 & & 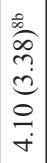 & & $\begin{array}{l}\hat{\sigma} \\
\grave{c} \\
n \\
\infty \\
\dot{r}\end{array}$ & 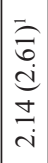 & & 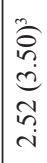 & $\begin{array}{l}\hat{n} \\
n \\
\tilde{n} \\
\infty \\
\tilde{n} \\
n \\
n\end{array}$ & 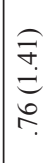 & \\
\hline & & 气ิ & 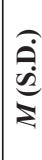 & & 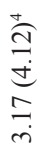 & $\begin{array}{l}\widehat{8} \\
\dot{ \pm} \\
8 \\
\text { i }\end{array}$ & 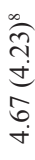 & & 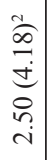 & $\begin{array}{l}\overparen{\sigma} \\
\dot{0} \\
\dot{c} \\
\hat{\sigma} \\
\dot{n}\end{array}$ & $\begin{array}{l}\hat{\bar{m}} \\
\tilde{n} \\
\tilde{n} \\
\tilde{\infty} \\
\dot{r}\end{array}$ & & 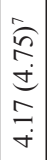 & & $\begin{array}{l}n \\
\infty \\
0 \\
\stackrel{n}{0} \\
m \\
m \\
m\end{array}$ & 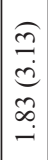 & & 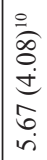 & 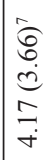 & $\begin{array}{l}\tilde{m} \\
\stackrel{n}{n} \\
\tilde{n} \\
\infty \\
i\end{array}$ & \\
\hline \multirow{6}{*}{ 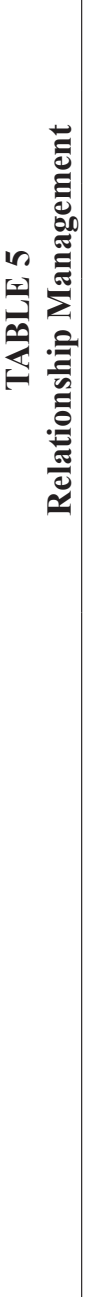 } & \multirow{3}{*}{\multicolumn{2}{|c|}{ 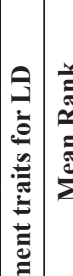 }} & $\mathbf{N}$ & †ి. & $\stackrel{\vec{n}}{\rightarrow}$ & $\tilde{n}$ & $\underset{+}{\rightarrow}$ & $\stackrel{2}{i}$ & $\mid \begin{array}{c}\vec{\infty} \\
\vec{T}\end{array}$ & $\stackrel{\vec{m}}{\rightarrow}$ & 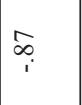 & $\stackrel{\infty}{\stackrel{p}{i}}$ & $\underset{i}{ \pm}$ & ?n & $\hat{n}$ & 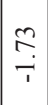 & $\underset{i}{0}$ & & & & $\begin{array}{l}\hat{\mathbb{J}} \\
0 \\
0\end{array}$ \\
\hline & & & 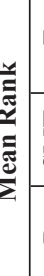 & 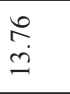 & $\stackrel{\widehat{\vartheta}}{\underline{\jmath}}$ & $\stackrel{n}{n}$ & $\begin{array}{l}\vec{\sim} \\
\stackrel{\sim}{n}\end{array}$ & $\begin{array}{l}\infty \\
\tilde{n} \\
\ddot{n}\end{array}$ & $\begin{array}{l}n \\
\mathfrak{r} \\
n \\
n\end{array}$ & $\begin{array}{l}n \\
\tilde{n} \\
\dot{n}\end{array}$ & $\begin{array}{l}\infty \\
\tilde{n} \\
\end{array}$ & 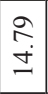 & 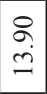 & $\begin{array}{l}\tilde{\sigma} \\
\stackrel{\sim}{2}\end{array}$ & $\begin{array}{l}\stackrel{0}{1} \\
\stackrel{ \pm}{ \pm}\end{array}$ & $\begin{array}{l}\text { సे } \\
\stackrel{n}{2}\end{array}$ & $\begin{array}{l}\stackrel{\cap}{+} \\
\pm\end{array}$ & & & & \\
\hline & & & $\theta$ & $\begin{array}{l}\infty \\
\dot{I} \\
\end{array}$ & $\begin{array}{l}\text { त̂ } \\
\infty \\
\infty\end{array}$ & $\begin{array}{l}\stackrel{\cap}{n} \\
\stackrel{n}{n}\end{array}$ & $\stackrel{n}{\stackrel{n}{6}}$ & $\stackrel{\Xi}{\sigma}$ & $\begin{array}{c}\sigma \\
\infty \\
\infty\end{array}$ & $\stackrel{m}{\stackrel{m}{I}}$ & 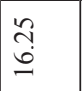 & $\begin{array}{l}\stackrel{\sim}{c} \\
=\end{array}$ & $\begin{array}{l}m \\
\stackrel{ \pm}{ \pm}\end{array}$ & $\tilde{n}$ & $\begin{array}{l}\infty \\
0 \\
\dot{m}\end{array}$ & م̊ & 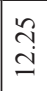 & & & & \\
\hline & 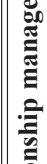 & $\sum_{\infty}^{\infty}$ & 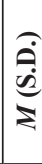 & 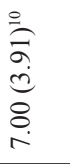 & 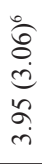 & $\begin{array}{l}\text { } \\
\hat{S} \\
\dot{ \pm} \\
\infty \\
+ \\
+ \\
+\end{array}$ & 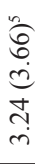 & 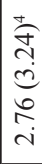 & 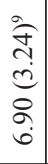 & 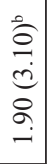 & $\begin{array}{l}\widehat{\hat{\infty}} \\
\stackrel{d}{d} \\
\vec{\infty} \\
\stackrel{-}{-}\end{array}$ & 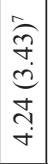 & 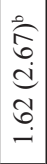 & 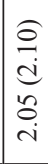 & 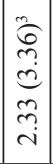 & 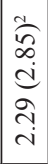 & 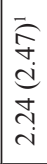 & & & & 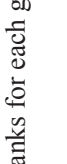 \\
\hline & 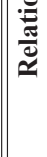 & 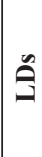 & 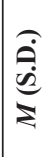 & 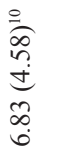 & 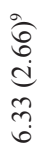 & 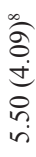 & $\begin{array}{l}\hat{\sigma} \\
\infty \\
\tilde{n} \\
\infty \\
\infty \\
\dot{+}\end{array}$ & 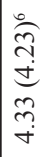 & $\mid \begin{array}{l}\widehat{\curvearrowright} \\
\hat{n} \\
\dot{n} \\
\hat{\sigma} \\
\dot{r}\end{array}$ & $\begin{array}{c}\tilde{\sigma} \\
\infty \\
\dot{c} \\
\hat{\sigma} \\
\dot{m} \\
\dot{n}\end{array}$ & $\begin{array}{l}\frac{1}{b} \\
+ \\
\dot{d} \\
m \\
m \\
m\end{array}$ & 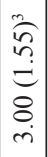 & $\begin{array}{l}\vec{\sigma} \\
\vec{b} \\
\dot{c} \\
m \\
\tilde{c} \\
i\end{array}$ & 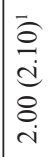 & 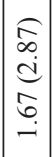 & $\begin{array}{l}\underset{\text { J }}{\text { I }} \\
=\end{array}$ & 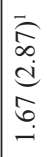 & & & & 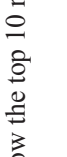 \\
\hline & & & & 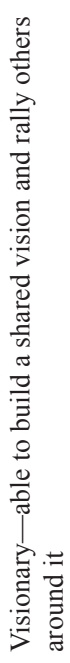 & 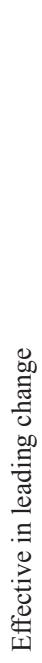 & 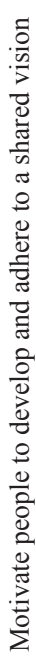 & 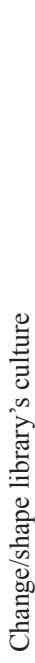 & 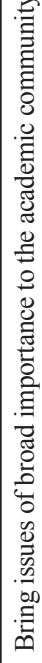 & 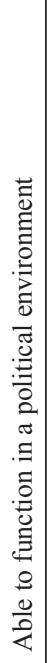 & 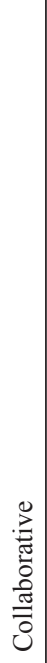 & 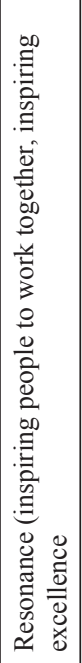 & 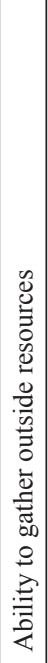 & 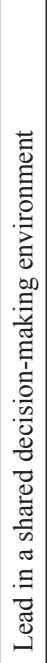 & 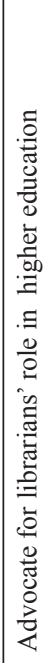 & 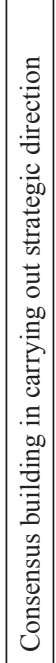 & 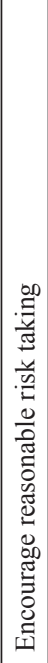 & 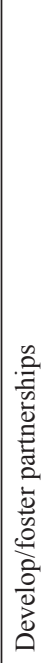 & 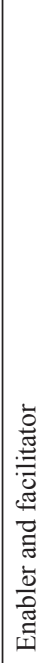 & 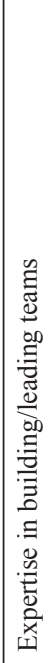 & 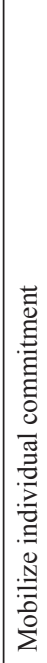 & 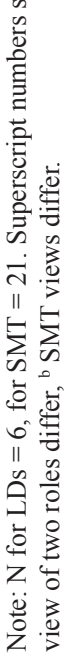 \\
\hline
\end{tabular}




\begin{tabular}{|c|c|c|}
\hline \multicolumn{3}{|c|}{$\begin{array}{c}\text { TABLE } 6 \\
\text { Most Important Ideal Library Director Traits }\end{array}$} \\
\hline Ranked traits & M (S.D.) & Mean Rank \\
\hline Know where he/she is going - taking the organization & $7.93(2.99)$ & $3.54^{1}$ \\
\hline Articulate direction for library & $7.14(3.35)$ & $3.17^{1}$ \\
\hline Visionary - able to build a shared vision and rally others to it & $6.96(3.98)$ & $3.22^{2}$ \\
\hline Ability to function in a political environment & $6.19(3.55)$ & $2.70^{2}$ \\
\hline Motivate people to develop and adhere to a shared vision & $4.70(4.02)$ & $2.37^{2}$ \\
\hline Ability to gather outside resources & $3.96(3.13)$ & \\
\hline \multicolumn{3}{|c|}{$\begin{array}{l}\text { Note: Rankings of the importance of traits in the LD role are presented for the sample as a whole }(N= \\
\text { 27). The items with the highest } 5 \text { averages (including any where the ranks were tied) were selected and } \\
\text { are shown. Items marked }{ }^{1} \text { are statistically comparable in rank }\left[\mathrm{X}^{2}(1)=.80, n s\right] \text { and rank higher than } \\
\text { items marked }{ }^{2}\left[\mathrm{X}^{2}(4)=9.97, p<.05\right] \text {. Final trait did not rank among the top five but was added for } \\
\text { comparison purposes. }\end{array}$} \\
\hline
\end{tabular}

ranked with a superscript 2 . The two traits ranked as most important for an ideal LD were knowing where he or she is taking the organization and articulating a direction for the library. The second set of traits considered important for an LD included being visionary - able to build a shared vision and rally others around it, being able to function in a political environment, and being able to motivate people to develop and adhere to a shared vision. Although the ability to gather outside resources was not among the top traits considered as most important for an LD, it is listed in this table for comparison and discussion.

Ideal senior management team mem- ber traits. Table 7 shows the frequencies and mean ranks for traits that both groups considered the most important for the ideal SMT's role. The top trait identified is the cognitive ability to deal with complex scenarios or situations. All other traits identified as most important for an ideal SMT were from either the social awareness domain (2 traits) or the relationship management domain (4 traits). Both these domains are defined as those clusters of EI traits that facilitate working with others.

Ideal shared leadership traits. Table 8 shows the frequencies and mean ranks considered most important for both the LD and SMT ideal roles. Traits listed as

\begin{tabular}{|c|c|c|}
\hline \multicolumn{3}{|c|}{$\begin{array}{l}\text { TABLE } 7 \\
\text { Most Important Ideal Senior Management Team Member Traits }\end{array}$} \\
\hline Ranked traits & M (S.D.) & Mean Rank \\
\hline Cognitive ability to deal with complex scenarios or situations & $6.07(3.69)$ & $4.94^{1}$ \\
\hline $\begin{array}{l}\text { Ability to understand, anticipate, and harness native } \\
\text { behaviors or approaches of staff }\end{array}$ & $4.30(4.13)$ & $3.93^{1}$ \\
\hline Lead in a shared decision-making environment & $4.11(3.62)$ & $4.04^{1}$ \\
\hline Consensus building in carrying out strategic direction & $3.74(3.76)$ & $3.98^{1}$ \\
\hline Accessible to others & $3.63(3.50)$ & $3.70^{1}$ \\
\hline Expertise in building and leading teams & $3.56(3.53)$ & $3.67^{1}$ \\
\hline Enabler and facilitator & $3.22(3.80)$ & $3.74^{1}$ \\
\hline \multicolumn{3}{|c|}{$\begin{array}{l}\text { Note: Rankings of the importance of traits in the SMT role are presented for the sample as a whole }(N \\
=27) \text {. The items with the highest } 5 \text { averages (including any where the ranks were tied) were selected } \\
\text { and are shown. Items marked }{ }^{1} \text { are statistically comparable in rank }\left[\mathrm{X}^{2}(6)=7.39, n s\right] \text {. }\end{array}$} \\
\hline
\end{tabular}




\begin{tabular}{|c|c|c|}
\hline \multicolumn{3}{|c|}{$\begin{array}{c}\text { TABLE } 8 \\
\text { Most Important Shared Ideal Leadership Traits }\end{array}$} \\
\hline Ranked traits & M (S.D.) & Mean Rank \\
\hline Ability to listen and delegate & $7.00(2.04)$ & $4.52^{1}$ \\
\hline Having integrity & $5.57(3.07)$ & $3.63^{1}$ \\
\hline Exercises good judgment & $5.43(2.89)$ & $3.56^{1}$ \\
\hline Good interpersonal/people skills & $4.80(3.21)$ & $3.39^{1}$ \\
\hline Effective in leading change & $4.35(2.49)$ & $3.02^{2}$ \\
\hline $\begin{array}{l}\text { Realistic understanding of oneself; emotions, } \\
\text { strengths, weaknesses, needs, and drives }\end{array}$ & $4.00(3.86)$ & $2.89^{2}$ \\
\hline \multicolumn{3}{|c|}{$\begin{array}{l}\text { Note: Rankings of the importance of traits in the LD and SMT role were averaged into one value for } \\
\text { the sample as a whole }(N=27) \text {, for which the means are presented above. The items with the highest } \\
5 \text { averages (including any where the ranks were tied) were selected and are shown. Items marked }{ }^{1} \\
\text { are statistically comparable in rank }\left[\mathrm{X}^{2}(3)=4.44, n s\right] \text { and rank higher than items marked }{ }^{2}\left[\mathrm{X}^{2}(5)=\right. \\
13.23, p<.03] \text {. }\end{array}$} \\
\hline
\end{tabular}

most important included the ability to listen and delegate, having integrity, exercising good judgment, and having good interpersonal skills. Two other traits that were considered somewhat less important were effectiveness in leading change and having a realistic self-understanding. The one leadership trait that received no rating by either group for either role was that of narcissism (at an acceptable level).

\section{Hypothesis Testing}

Hypothesis 1 (no significant difference in the competencies LDs selected for an ideal LD or an ideal SMT) was supported except for one trait. Directors ranked attracting, building, and retaining talent as significantly more important for an LD to possess than for an SMT (LDs' mean negative ranks $=0.00$, mean positive ranks $=3.00, z=-2.03, p<.04$ ). Hypothesis 2 (no significant difference in the competencies SMTs selected for both roles) was supported with eight exceptions. Competencies that senior management team members identified as more important for an LD than for an SMT included knowing where he or she is taking the organization (SMTs' mean negative ranks $=3.50$, mean positive ranks $=8.83, z=-3.37, p<.001)$, articulating a direction for the library (SMTs' mean negative ranks $=0.00$, mean positive ranks $=7.50, z=-3.31, p<.001)$, and being articu- late (SMTs' mean negative ranks $=0.00$, mean positive ranks $=5.50, z=-2.81, p<$ .005). SMTs also ranked several competencies as more important for an SMT than an LD to possess, including being able to listen and delegate (SMTs' mean negative ranks $=8.54$, mean positive ranks $=8.33$, $z=-2.24, p<.03)$, respecting individuality and diversity (SMTs' mean negative ranks $=5.50$, mean positive ranks $=1.50, z$ $=-2.11, p<.04)$, being accessible to others (SMTs' mean negative ranks $=6.50$, mean positive ranks $=6.50, z=-2.04, p<.04)$, being collaborative (SMTs' mean negative ranks $=7.11$, mean positive ranks $=4.67, z$ $=-1.97, p<.05)$ and being able to lead in a shared decision-making environment (SMTs' mean negative ranks $=9.00$, mean positive ranks $=4.00, z=-2.73, p<.006$ ).

\section{Discussion}

The findings suggest that different competencies are needed by individuals in each role, reflecting the primary tasks of that role. Often in an organization, the top leader's primary role is to create change while the director's management team focuses on running the organization and implementing change. ${ }^{39}$ The list of the five top-ranked competencies that all respondents consider most important for an LD to possess indicates that an LD must be able to create a vision for change, 
communicate that vision, and then motivate staff to support that change. Hernon and Rossiter also found that the five most valuable competencies respondents listed in the motivation domain for LDs were competencies focused on vision and persuasion - the ability to build a shared vision and rally others around it, to articulate a direction for the library, and to motivate people to develop and adhere to a shared vision. ${ }^{40}$ In other domains, their respondents also ranked the ability to function in a political environment and the ability to know where he or she is taking the organization as top competencies for an LD. These visionary and motivational skills are included as key leader/ director competencies in other studies. ${ }^{41}$

This study also found that LDs thought the trait "drive to achieve" was more important for an ideal LD's role than SMTs did. This difference may be due to the context in which each group interpreted the trait, with LDs thinking the trait referred to driving to achieve the library's vision and direction, whereas SMTs perhaps thinking that it referred to an LD's individual achievement. It may also be that the challenges facing LDs require them to be individually motivated to be successful. As one director observes in a discussion about ARL director competencies, directors' experiences are often "not fun or pleasant, and difficult decisions must be made without always having the support of staff or other campus administrators." ${ }^{42}$ LDs may recognize the sustaining value of a drive to succeed for their role, whereas SMTs may not.

It is interesting to note that the EI trait "narcissism (an acceptable level)" was the only EI trait in the survey that was not selected by any respondent, giving it a value of zero. This finding is similar to two other studies of what EI traits were valued by library directors. In one of those studies, narcissism as prized trait of a library director was chosen only once. ${ }^{43}$ In the second study, it was not chosen at all. ${ }^{44}$ This reaction to narcissism is not surprising, since the common view of this trait is that it is the antithesis of many EI traits. Narcissists are often defined as self-absorbed, vain, and egotistical and, at worst, are considered to have a psychological disorder. ${ }^{45}$ While some management writers argue that narcissistic traits might be valuable for leaders, ${ }^{46}$ from the consistency with which this trait is undervalued in these studies, library managers appear to be applying the more popular-and negative-concept of this trait.

One popular assumption is that an LD's top responsibility is obtaining money from outside donors, funding agencies, or other sources. ${ }^{47}$ Yet, in this study and others, that trait was not ranked among the five most important competencies for an LD. ${ }^{48}$ Perhaps respondents interpreted this as more of an LD's job responsibility than a competence or assumed that it would be more important for staff specializing in fundraising.

In contrast to the responsibilities of the director, the senior management team is often more directly focused on running the library, since it is the group "most responsible for strategic decision making and, by extension, such fundamental organizational outcomes as ... strategy, structure, and performance." 49 Thus, SMTs need people skills and strategic skills to be most successful in their organizational roles. The five top-ranked competencies all respondents chose for an ideal SMT show that SMTs must able to solve complex problems, to engage staff with diverse talents, to lead teams, to build consensus and share decision making. Interestingly, some of the lowest-ranked competencies indicated for directors in Hernon, Powell, and Young were the following: leading in a shared decisionmaking environment, interpersonal/ people skills, and conflict resolution - all competencies that respondents ranked highest for SMTs to possess in this study. ${ }^{50}$

SMTs considered it more important for SMTs to attract, build, and retain talent than LDs considered it important for the SMT role. As managers, SMTs are respon- 
sible for ensuring that they have the right mix of talent to meet new customer needs and must engage in succession planning as the population of academic library workers ages. ${ }^{51}$ Perhaps LDs are less aware of these needs than SMTs because SMTs have not communicated their staffing situations clearly to their directors or because LDs feel that the ability to attract and retain staff is an outcome of the LD's responsibilities to motivate and inspire.

On the other hand, LDs believed that respect for scholarship was more important for the SMTs than SMTS believed it was for their own role. LDs may interpret respecting scholarship as part of the ability to align the library with the broader academic enterprise that libraries serve, whereas SMTs may be more internally focused on the organization and may not think in this larger context when asked to identify the key competencies for their role.

Integrity, good judgment, an ability to listen, people skills, effectiveness in leading change, and self-understanding were ranked as the top competencies that any leader should possess and that individuals - no matter where they are in an organization - would like any leader they follow to possess. These foundational competencies complement the specific competencies of the LD and the SMT.

\section{Directions for Future Research}

Although there is a large body of research studying the chief economic officer's (CEO's) leadership skills and how the top leader affects organizational performance, ${ }^{52}$ workplace leadership presents researchers with additional layers of complexity since leadership can be exercised throughout the organization by individuals with varying levels of power, responsibility, and skill. ${ }^{53}$ Noting that leadership is often shaped by its context, one respondent in this study observed, "The roles of a director or assistant dean [SMT] vary in the organization, thus, requiring skills to match .... the best person in either role is the one that recognizes what is needed at that moment." Future research might explore the interdependent and perhaps changing relationship between top leaders and the leadership capacity and skills of individuals throughout the organization. Also, if ideal EI competencies vary by organizational role, it might be interesting to undertake a longitudinal study that follows a group of library managers to identify possible changes in the EI competencies they exercise, or which they perceive as needed, as their organizational roles and responsibilities change. A final area of future study could be to assess the EI traits possessed by library management teams, what traits they collectively need but lack, and how they proceed to learn those skills.

Because this study was limited in the geographic region it studied and the type of library, future research might extend the study of these core competencies to a broader sample of LDs and SMTs in nonARL libraries, perhaps even in non-U.S. libraries. Many studies have shown that leadership is a culturally dependent construct-does this hold true for leadership in academic libraries? Or does the nature and mission of academic librarianship transcend cultural differences, leading to a shared vision of the traits needed for academic library leaders? Beyond the library profession, it might be interesting to explore whether these lists of top traits offer a useful way to characterize the EI competencies of leaders and managers in nonlibrary organizations.

\section{Limitations of the Study}

Two conditions limit the study's applicability. First, the small sample size limits the reliability of the statistical analyses performed. Another limitation was touched on by respondents in Hernon and Rossiter's study of LDs' EI traits. Respondents noted that the importance of a trait may be contextual: that is, dependent on specific situations or organizations. As a result, they reported that they had difficulty choosing a limited number of traits. ${ }^{54}$ Their observations were echoed 
by three of the respondents in this study. One respondent stated that "it was very difficult to rank these 1-10-I don't have a lot of confidence that my answers would be the same if I took this [survey again] in two weeks." A second respondent found it difficult to put the competencies in a meaningful order, stating that "These competencies work together so it is hard to prioritize in a vacuum. Also, I think the relative priorities are in a narrow band."

A third limitation of this study is that some of the traits include several components that could be given different priorities for different roles. For example, the trait "attract, build, and retain talent" includes three potentially very different aspects of staff management. LDs rated this trait second highest in importance for themselves and lowest out of ten for the SMT role. However, SMTs rated this as the highest trait in the social awareness domain for their role as well as third highest for the LD. The difference in rankings between the groups may not be due to a difference in role interpretation but a difference in emphasis within the competence. Perhaps LDs focused on attracting staff as critical to an LD's role, and SMTs responded positively to the aspects of building and retaining staff. The breadth of some competencies permits wide interpretation.

\section{Conclusion}

The three lists developed from this study - the ideal traits for a library director and for a senior management team member and the list of shared ideal leadership traits for all leaders - create a foundation of leader skills that may be useful in a number of venues. Although some of the traits identified as most important build on an individual's innate personal qualities, many researchers and practitioners agree that EI traits can be acquired and strengthened through practice and training. ${ }^{55}$ EI skill improvement can be developed through formal coursework, workshops and leadership institutes, mentoring, on-the-job coach- ing, analytical tools, and, finally, rigorous self-scrutiny and practice.

Library directors and senior management team members can use these lists as an assessment tool to analyze the traits they collectively possess and those they might need to acquire. As hiring opportunities arise, they can use the lists, informed by their analyses, to help them recruit and hire to balance their team's overall EI traits. Graduate schools and leadership institutes can use these lists to assess pretraining skills, offer focused EI training, and identify posttraining outcomes. Newer librarians wishing to develop their leadership skills can use the list of shared traits for all leaders and ideal SMT traits to focus their own development efforts, while SMT members interested in a director position can become more competitive by comparing their EI traits to those of an ideal library director and developing any missing skills.

While these three lists of EI traits do not comprehensively define the skills and abilities an academic library leader needs to be successful, they are critical to realizing a core responsibility of leadership_influencing people to work together to achieve a purpose. The top EI traits identified in this study are tools leaders can use to build that social contract between leaders and followers by identifying and communicating a vision, motivating people to buy into that vision, and then organizing them to work together effectively toward that vision. The respondents' choices of traits by organizational roles reflect a sophisticated and nuanced understanding that leadership is not just the responsibility of the man or woman at the top but is a shared and interdependent endeavor. Just as the organizational responsibilities of director and senior management team member complement each other, so do the traits needed to fulfill those roles effectively.

It would be interesting to extend this exploration of role-based traits to another level within the senior management team members' roles in the organization. When 
they are interacting with their middle management team members, do they employ more of the ideal traits of a director to complement the traits they expect or experience from their middle management team members? If individuals from more levels and other areas of responsibility were queried, would other levels or groupings of EI traits emerge as ideal sets for different roles within the library organization?

The results of this study confirm Goleman's conclusion that no one leader can or needs to develop competency in the full range of EI traits leaders need. ${ }^{56}$ Academic library leaders do not need to possess every EI trait to ensure organizational success. In fact, quite the opposite, since no one individual can be perfect and "The best ones don't try to be-they concentrate on honing their strengths and find others who can make up for their limitations." 57 If a library's director and his or her senior management team recognize the complementary nature of their roles and partner to build the EI traits that would make them the most effective, they will then be better able to perform as a true "team at the top." By understanding the shared and complementary nature of their leadership, they can work together to create an emotionally intelligent organization that can more effectively achieve the library's vision and goals.

\section{Notes}

1. Daniel Goleman, Richard Boyatzis, and Annie McKee, Primal Leadership (Boston: Harvard Business School Press, 2002), 5.

2. Daniel Goleman, Working with Emotional Intelligence (New York: Bantam, 1998), 318.

3. Daniel Goleman, "An EI-Based Theory of Performance," in The Emotionally Intelligent Workplace, eds. C. Cherniss and D. Goleman (San Francisco: Jossey-Bass, 2001), 27-44.

4. Victor Dulewicz and Malcolm Higgs, "Emotional Intelligence: A Review and Evaluation Study," Journal of Managerial Psychology 15 (2000): 341-72; Shelley A. Kirkpatrick and Edwin A. Locke, "Leadership: Do Traits Matter?" The Executive 5 (1991): 48-60; John D. Mayer and Peter Salovey, "The Intelligence of Emotional Intelligence," Intelligence 17 (1993): 433-42; Richard McBain, "Emotional Intelligence: A Review of an Emerging Construct," Manager Update 15 (2004): 21-34; Moshe Zeidner, Gerald Matthews, and Richard D. Roberts, "Emotional Intelligence in the Workplace: A Critical Review," Applied Psychology: An International Review 53 (2004): 371-99.

5. Goleman, Boyatzis, and McKee, Primal Leadership, 28.

6. Richard E. Boyatzis, The Competent Manager: A Model for Organizational Effectiveness (New York: Wiley-Interscience, 1982); David C. McClelland, "Identifying Competencies with BehavioralEvent Interviews," Psychological Science 9 (1998): 331-39.

7. Abraham Carmeli, "The Relationship between Emotional Intelligence and Work Attitudes, Behavior and Outcomes: An Examination Among Senior Managers," Journal of Managerial Psychology 18 (2003): 788-813; Goleman, "An EI-Based Theory of Performance"; Malcolm Higgs and Paul Aitken, "Research Note: An Exploration of the Relationship between Emotional Intelligence and Leadership Potential," Journal of Managerial Psychology 18 (2003): 814-23.

8. Randall S. Peterson et al., "The Impact of Chief Executive Officer Personality on Top Management Team Dynamics: One Mechanism by which Leadership Affects Organizational Performance," Journal of Applied Psychology 88 (2003): 795-808.

9. Jennifer M. George, "Emotions and Leadership: The Role of Emotional Intelligence," $\mathrm{Hu}$ man Relations 53 (2000):1027-55; Anneloes M.L. Raes et al., “Top Management Team and Middle Managers: Making Sense of Leadership," Small Group Research 38 (2007): 360-86.

10. Carole Page et al., "It's the Situation I'm In: The Importance of Managerial Context to Effectiveness," Journal of Management Development 22 (2003): 843.

11. Jon R. Katzenbach, Teams at the Top (Boston: Harvard Business School Press, 1998), 2.

12. Zeidner et al., "Emotional Intelligence in the Workplace."

13. Ibid., 379.

14. Robert Hogan and Robert B. Kaiser, "What We Know about Leadership," Review of General Psychology 9 (2005): 169-80.

15. F. William Brown and Dan Moshavi, "Transformational Leadership and Emotional Intelligence: A Potential Pathway for an Increased Understanding of Interpersonal Influence," Journal of Organizational Behavior 26 (2005): 867-71; Carmeli, "Emotional Intelligence and Work"; 
Dulewicz and Higgs, "Emotional Intelligence: A Review"; Victor Dulewicz and Malcolm Higgs, "Leadership at the Top: The Need for Emotional Intelligence in Organizations," International Journal of Organizational Analysis 11 (2003): 193-210; Lisa Gardner and Con Stough, "Examining the Relationship between Leadership and Emotional Intelligence in Senior Level Managers," Leadership \& Organization Development Journal 23 (2002): 68-78; Higgs and Aitken, "Research Note"; David Rosete and Joseph Ciarrochi, "Emotional Intelligence and Its Relationship to Workplace Performance Outcomes of Leadership Effectiveness," Leadership and Organization Development Journal 26 (2005): 388-99.

16. Dulewicz and Higgs, "Leadership at the Top."

17. Ibid., 193.

18. Alice M. Isen, "Positive Affect as a Factor in Organizational Behavior," Research in Organizational Behavior 13 (1991): 1-53.

19. Armenio Rego et al., "Leaders Self-Reported Emotional Intelligence and Perceived Employee Creativity: An Exploratory Study," Creativity and Innovation Management 16 (2007): 250-64; Elizabeth C. Stubbs, "Emotional Intelligence Competencies in the Team and Team Leader: A Multi-Level Examination of the Impact of Emotional Intelligence on Group Performance (Ph.D. diss., Case Western Reserve University, Cleveland, 2005).

20. Jennifer M. George, "Leader Positive Mood and Group Performance: The Case of Customer Service," Journal of Applied Social Psychology 25 (1995): 778-94.

21. Rosete and Ciarrochi, "Emotional Intelligence."

22. Susan E. Heiken, “The Perceived Relationship between Emotional Intelligence and Leadership Effectiveness in School Leaders: A Comparison of Self Ratings with Those of Superiors and Reports" (Ph.D. diss., Wilmington College, Ohio, 2006), 9.

23. Hiu-Wen Vivian Tang, "A Cross-Cultural Investigation of Academic Leaders' Emotional Intelligence and Leadership Effectiveness in Taiwan and the United States" (Ph.D. diss., Texas A\&M University, 2007).

24. Janice E. Noble, "The Dean in California Community Colleges: The Expectation of Emotional Intelligence" (Ph.D. diss., Capella University, 2006).

25. James O’Toole, Jay Galbraith Jr., and Edward E. Lawler III, “When Two (or More) Heads Are Better Than One: The Promise and Pitfalls of Shared Leadership," California Management Review 44 (2002): 65.

26. Ibid., 75 .

27. Vanessa U. Druskat and Steven B. Wolff, “Group Emotional Intelligence and Its Influence on Group Effectiveness," in The Emotionally Intelligent Workplace: How to Select for, Measure, and Improve Emotional Intelligence in Individuals, Groups, and Organizations, eds. C. Cherniss and D. Goleman (San Francisco: Jossey-Bass, 2001), 132-55; Crissie M. Frye, Rebecca Bennett, and Sheri Caldwell, "Team Emotional Intelligence and Team Interpersonal Process Effectiveness," Mid-American Journal of Business 21 (2006): 49-56; Anna L. Green et al., "The Use of Multiple Intelligences to Enhance Team Productivity," Management Decision 43 (2005): 349-59; Wendy M. Williams and Robert J. Sternberg, "Group Intelligence: Why Some Groups Are Better Than Others," Intelligence 12 (1988): 351-77.

28. Vanessa Druskat, "Building the Emotional Intelligence of Groups," Harvard Business Review 79 (2001): 80-90; Goleman, Working with Emotional Intelligence, 219.

29. Goleman, Boyatzis, and McKee, Primal Leadership, 52.

30. Carmeli, "Emotional Intelligence and Work," 806.

31. Gardner and Stough, "Examining the Relationship between Leadership and Emotional Intelligence in Senior Level Managers."

32. Bernard M. Bass and Ronald E. Riggio, Transformational Leadership, 2nd ed. (Mahwah, N.J.: Lawrence Erlbaum Association, 2006), 3, 5 .

33. Peter Hernon and Nancy Rossiter, “Emotional Intelligence: Which Traits Are Most Prized?" College \& Research Libraries 67 (2006): 260-75.

34. Ibid., 271.

35. Peter Hernon, "General Leadership Traits," in Academic Librarians as Emotionally Intelligent Leaders, eds. P. Hernon, J. Giesecke, and C. Alire (Westport, Conn.: Libraries Unlimited, 2007), $43-56$.

36. U.S. Bureau of the Census, Geography Division (n.d.), "Census Regions and Divisions of the United States." Available online at www.census.gov/geo/www/us_regdiv.pdf. [Accessed 5 November 2007].

37. Hernon and Rossiter, "Emotional Intelligence."

38. Private communication from Hernon, Nov. 2007.

39. Peter Hernon, Ronald R. Powell, and Arthur P. Young, The Next Library Leadership: Attributes of Academic and Public Library Directors (Westport, Conn.: Libraries Unlimited, 2003), 49; Peter G. Northouse, Leadership: Theory and Practice, 3rd ed. (Thousand Oaks, Calif.: Sage Publications, 
2004), 9.

40. Hernon and Rossiter, "Emotional Intelligence."

41. Hernon, "General Leadership Traits"; Donald E. Riggs, "Ineffective (Bad!) Leadership," in Making a Difference: Leadership and Academic Libraries, eds. P. Hernon and N. Rossiter (Westport, Conn.: Libraries Unlimited, 2007), 181-88; Becky Schreiber and John Shannon, “Developing Library Leaders for the 21st Century," Journal of Library Administration 32 (2001): 35-57.

42. Hernon, Powell, and Young, The Next Library Leadership, 61.

43. Hernon and Rossiter, "Emotional Intelligence," 264.

44. Hernon, Giesecke, and Alire, Academic Librarians as Emotionally Intelligent Leaders, 47.

45. "Narcissism." Available online at http://en.wikipedia.org/wiki/Narcissism. [Accessed 1 February 2009].

46. Michael Maccoby, "Narcissistic Leaders: The Incredible Pros, the Inevitable Cons," in Harvard Business Review on What Makes a Leader (Boston: Harvard Business School Publishing Corporation, 2001), 27-52.

47. Susan K. Martin, "The Changing Role of the Library Director: Fund-Raising and the Academic Library," The Journal of Academic Librarianship 24 (1998): 3-10; Mark D. Winston and Lisa Dunkley, "Leadership Competencies for Academic Librarians: The Importance of Development and Fund-raising," College \& Research Libraries 63 (2002): 171-82.

48. Hernon and Rossiter, "Emotional Intelligence," 267.

49. Sydney Finkelstein and Donald C. Hambrick, Strategic Leadership: Top Executives and Their Effects on Organizations (St. Paul, Minn.: West, 1996), 116.

50. Hernon, Powell and Young, The Next Library Leadership, 176.

51. Stanley J. Wilder, "New Hires in Research Libraries: Demographic Trends and Hiring Priorities," in Human Resource Management in Today's Academic Library, eds. J. Simmons-Welburn and B. McNeil (Westport, Conn.: Libraries Unlimited, 2004): 19-26.

52. Boyatzis, The Competent Manager; Finkelstein and Hambrick, Strategic Leadership; William Joyce, Nitin Nohria, and Bruce Roberson, "What Really Works?" in The Future of Human Resource Management, eds. M. Losey, S. Meisinger, and D. Ulrich (Hoboken, N.J.: John Wiley \& Sons, 2005), 221.

53. Navigating Change: How CEOs, Top Teams, and Boards Steer Transformation, eds. Donald C. Hambrick, David A. Nadler, and Michael L. Tushman (Boston: Harvard Business School Press, 1998); Katzenbach, Teams at the Top; O'Toole et al., "When Two (or More) Heads Are Better Than One."

54. Hernon and Rossiter, "Emotional Intelligence," 274.

55. Bass and Riggio, Transformational Leadership; Warren Bennis and Joan Goldsmith, Learning to Lead, 3rd ed. (New York: Basic Books, 2003).

56. Goleman, Boyatzis, and McKee, Primal Leadership, 28.

57. Deborah Ancona et al., "In Praise of the Incomplete Leader," Harvard Business Review 85 (2007): 92. 


\section{Appendix: Domains \& Associated Traits}

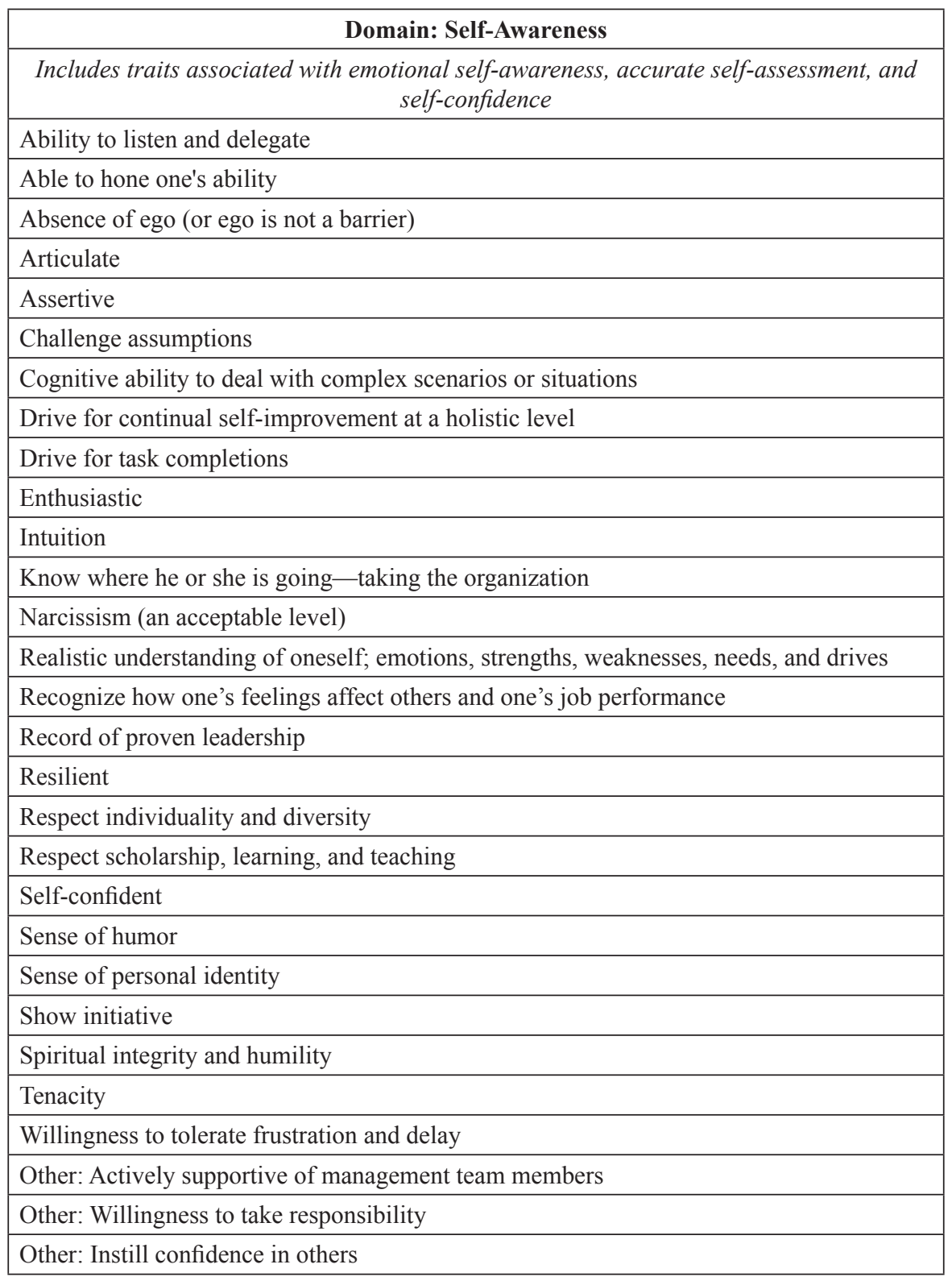




\begin{tabular}{|c|}
\hline Domain: Self-Management \\
\hline $\begin{array}{c}\text { Includes traits associated with self-control, transparency, adaptability, achievement, } \\
\text { initiative, and optimism }\end{array}$ \\
\hline Ability to compromise \\
\hline Ability to figure out what is going on without having to be told \\
\hline Articulate direction for the library \\
\hline Ask the "right"/“tough" question \\
\hline Broad knowledge of issues \\
\hline Comfortable with ambiguity \\
\hline Comfortable in making judgment calls \\
\hline Comfortable with change \\
\hline Commitment to job, organization, institution, and profession \\
\hline Courage of convictions \\
\hline Diplomatic \\
\hline Driven to achieve beyond expectations, motivation \\
\hline Endurance \\
\hline Evenhanded \\
\hline Flexible in adapting to change or overcoming obstacles \\
\hline Good oral and written presentation skills \\
\hline Handle stress well \\
\hline High energy level \\
\hline Honesty \\
\hline Initiative \\
\hline $\begin{array}{l}\text { Innovative, creative, seeks out, and acts on, challenges and new opportunities, think } \\
\text { outside the box }\end{array}$ \\
\hline Integrity \\
\hline Open-minded \\
\hline Optimism (even in the face of failure) \\
\hline Propensity for reflection \\
\hline Realistic organizational awareness \\
\hline Receptivity to change \\
\hline Sense of perspective \\
\hline Skill at diagnostic, strategic, and tactical reasoning \\
\hline Stable temperament and ability to maintain an emotional balance under constant tensions \\
\hline Trustworthy \\
\hline
\end{tabular}




\begin{tabular}{|l|}
\hline \multicolumn{1}{|c|}{ Domain: Social Awareness } \\
\hline \multicolumn{1}{|c|}{ Includes traits associated with empathy, organizational awareness, and service } \\
\hline Ability to understand, anticipate, and harness native behaviors or approaches of staff \\
\hline Accessible to others \\
\hline Attract, build, and retain talent \\
\hline Being open-minded \\
\hline Comfortable with team culture \\
\hline Create an environment that fosters accountability \\
\hline Cross-cultural sensitivity \& record of achievement \\
\hline Empathy \\
\hline Exercises good judgment \\
\hline Figure out what is going on without having to be told \\
\hline Genuine belief in the abilities of, and the good faith of, others in the organization \\
\hline Give praise generously \\
\hline Good interpersonal/people skills \\
\hline Good listening skills \\
\hline Having integrity \\
\hline Interested in others \\
\hline Keep organization focused on high-quality service \\
\hline Thoughtfully consider the feelings of others \\
\hline Treat others as equals \\
\hline Treat people with dignity/respect \\
\hline Understand small-group dynamics \\
\hline Wide range of work experiences in different sizes of organizations and different job levels \\
\hline
\end{tabular}




\begin{tabular}{|c|}
\hline Domain: Relationship Management \\
\hline $\begin{array}{c}\text { Includes traits associated with inspiration, influence, developing others, change catalyst, } \\
\text { conflict management, teamwork, and collaboration }\end{array}$ \\
\hline Ability to function in a political environment \\
\hline Ability to gather outside resources \\
\hline Advocate for librarians' role in higher education \\
\hline $\begin{array}{l}\text { Bring issues of broad importance to the academic community, fostering wide discussion } \\
\text { and action when appropriate }\end{array}$ \\
\hline Build rapport with a wide circle of people \\
\hline Change/shape the library's culture \\
\hline Collaborative \\
\hline Consensus building in carrying out strategic direction \\
\hline Develop and foster partnerships \\
\hline Effective in leading change \\
\hline Enabler and facilitator \\
\hline Encourage reasonable risk taking \\
\hline Entrepreneurial \\
\hline Establish credibility with colleagues \\
\hline Expertise in building and leading teams \\
\hline Friendly (with a purpose) \\
\hline Good people networking skills \\
\hline Help participants in meetings, consortia, and cooperative endeavors to be results oriented \\
\hline Lead in a shared decision-making environment \\
\hline Mobilize individual commitment \\
\hline Motivate people to develop and adhere to a shared vision \\
\hline Nurture staff \\
\hline Persuasiveness \\
\hline Resonance (inspiring people to work together to solve problems, inspiring excellence) \\
\hline Serve as a role model of desired behavior \\
\hline Tolerate some mistakes \\
\hline Visionary - able to build a shared vision and rally others around to it \\
\hline
\end{tabular}

